\title{
A PRELIMINARY SURVEY OF THE INCIDENCE AND AETIOLOGY OF SPINAL PARALYSIS
}

\author{
By A. C. Buchan, G. E. Fulford, P. Harris, E. Jellinek, W. G. KerR, I. Kirkland, \\ J. E. Newsam and G. D. ST ARK \\ From the Departments of Child Life and Health, Clinical Surgery, Medical Neurology, \\ Orthopaedic Surgery, Paediatric Surgery, Surgical Neurology, University of Edinburgh; \\ and the Spinal Unit, Edenhall Hospital, Edinburgh
}

As doctors who work in hospital departments and units concerned with the investigation and management of patients with spinal paralysis are liable to see a selected group of these patients, an attempt has been made to obtain some idea of the actual incidence and aetiology of spinal paralysis in one geographical area, admitted to hospital during a single year, 1968 .

Incidences. During this year, specialists in plastic, orthopaedic and neurological surgery, in medical neurology, in paraplegia as a whole, in paediatric medicine and surgery, and in urological surgery, involved with the care of patients with spinal paralysis, saw and admitted 3 IO such patients to hospital. One hundred and forty-one were first admissions and 169 re-admissions. However, as some patients were re-admitted on more than one occasion, the total number of admissions in that year was 448 . Of the series $3 \mathrm{I} \cdot 6$ per cent. of all admissions were in hospital for less than one month, and 16.7 per cent. for more than three months. Seventy five per cent. of these patients lived in the South-East region of Scotland, and about 20 per cent. came from the West of Scotland.

Aetiology. Among these 3 Io patients, 138 (44.5 per cent.) had spina bifida; this was by far the commonest cause of spinal paralysis in this group. It is known that in Great Britain some 2,700 babies are born each year with spina bifida and a severe neurological lesion amounting to paraplegia. The next commonest cause was trauma, 65 patients (2I per cent.). Of the 39 patients ( 12.6 per cent.) with intervertebral disc disease, 35 had cervical lesions and these were usually in the form of severe cervical spondylotic myelopathy; 28 patients had a spinal neoplasm ( 9 per cent.); 27 had myelitis ( $8 \cdot 7$ per cent.), a term which included patients with multiple sclerosis, transverse myelitis or encephalo-myelitis. There was a miscellaneous group of 13 patients $(4 \cdot 2$ per cent.) which included vascular lesions of the spinal cord, and infections (Table I).

When considering aetiology in relation to age (Table II), it is clear that at the present time spina bifida is still predominantly a paediatric problem. Trauma is spread almost evenly through the $3 \mathrm{rd}, 4$ th, 5 th and 6 th decades; but intervertebral disc disorders are found in the 5 th, 6 th and in particular in the 7 th decade. Spinal neoplasms were seen in teenagers and in patients in the 5th, 6th and 7 th decades. Myelitis was commonest in the 5 th decade. 
TABLE I

Aetiology

\begin{tabular}{|l|c|c|}
\hline AETIOLOGY & $\begin{array}{c}\text { NUMBER OF } \\
\text { PATIENTS }\end{array}$ & $\%$ \\
\hline SPINA BIFIDA & 138 & 44.5 \\
TRAUMA & 65 & 21.0 \\
DISC DISEASE & 39 & 12.6 \\
NEOPLASM & 28 & 9.0 \\
MYELITIS & 27 & 8.7 \\
OTHER & 13 & 4.2 \\
\hline TOTALS & 310 & 100.0 \\
\hline
\end{tabular}

TABLE II

Aetiology in relation to Age and Sex Incidence

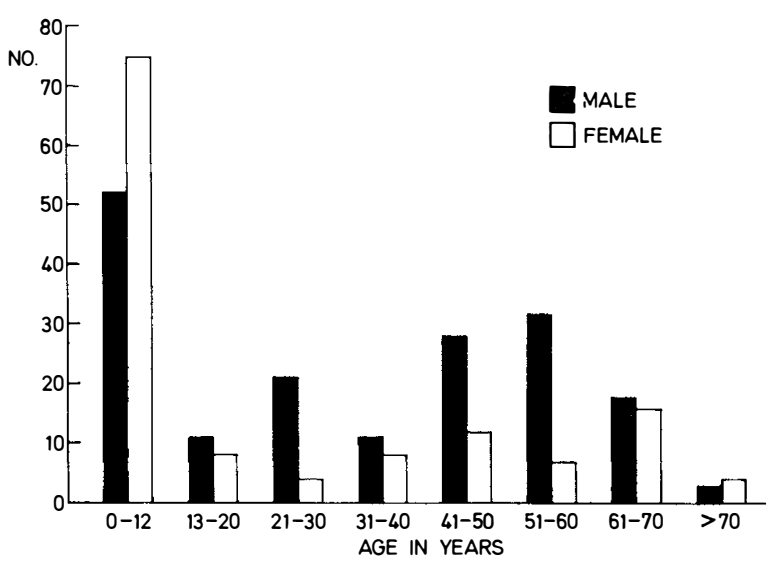

Sex Incidence and Age. As is shown in Table II, paraplegia is commoner in males, accounting for 56 per cent. of the present series. As it is known that the frequency of spina bifida in females and males is in the ratio of 1000:700, in the future an increase in the proportion of female paraplegic patients can be anticipated. Traumatic paraplegia is commoner in the male than in the female; there were 28 male and I I female patients. Forty-seven per cent. of the total number of patients in our series were 20 years of age or younger. 
Neurological Level. Table III illustrates the neurological level of the lesion in relation to the aetiology of the spinal paralysis, and it is seen that spina bifida usually affects the lumbo-sacral region of the cord and the cauda equina is

TABLE III

The Neurological Level

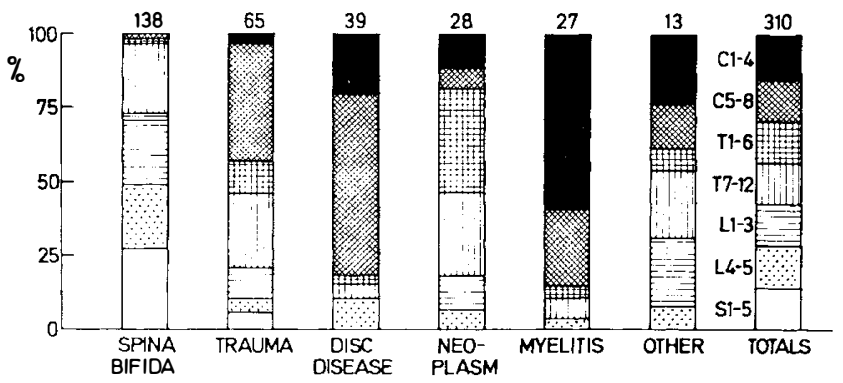

usually also involved. Almost 50 per cent. of the patients with a traumatic lesion had a cervical injury, and 20 per cent. had cauda equina damage. Thirty-five of the 39 disc lesions were in the cervical region, and the majority of these patients had mid, or high, cervical cord damage. Spinal neoplasms were to be found at all levels, but secondary neoplasms mainly affected the dorsal region. Most patients with myelitis, as defined in this study, had high cervical lesions, sometimes associated with brain-stem involvement.

Physical Disability. As is seen in Table IV, physical disability in spina bifida was divided almost equally into severe, moderate and mild, but in patients

TABLE IV

Physical Disability

PHYSICAL DISABILITY

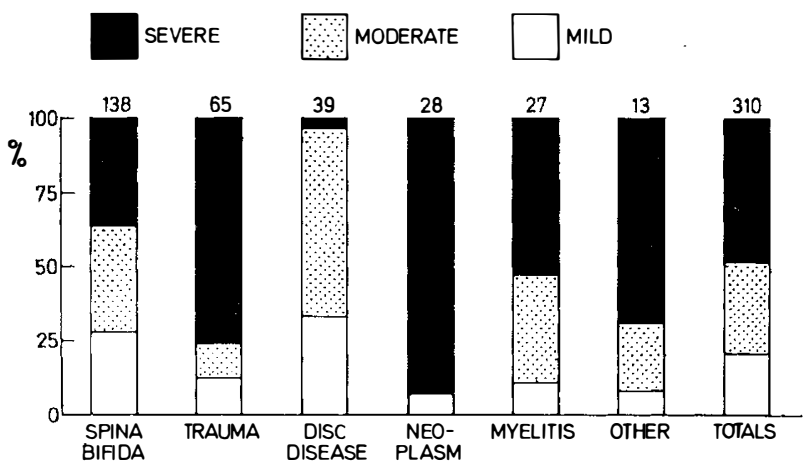

with spinal injury it was usually severe. Most of those who only had a mild disability, had an atlanto-axial dislocation or fracture-dislocation. We found that 
the majority of our patients with intervertebral disc lesions had partial spinal cord involvement but those with spinal neoplasms nearly all had severe physical disability and unfortunately the majority of these patients came to neurosurgeons at a late stage in the disease.

\section{TABLE V}

\section{Urinary Bladder Involvement}

BLADOER INVOLVEMENT

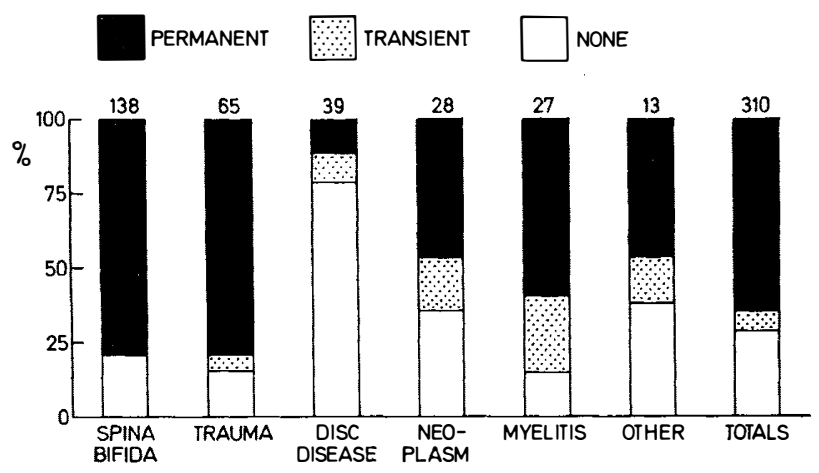

Urinary Bladder Involvement. An analysis of urinary bladder involvement and the aetiology of the spinal paralysis (Table V) showed that serious and permanent disturbance of urinary bladder function occurred in most of the patients who had spina bifida or spinal injury. Less severe or transient disturbance of bladder function occurred in patients with myelitis or spinal neoplasm, and only about 20 per cent. of patients with intervertebral disc disease had any bladder involvement. Of the 3 Io patients, 65 per cent. had 'permanent bladder paresis'.

\section{TABLE VI}

Situation at the End of 1968

SITUATION AT END OF 1968

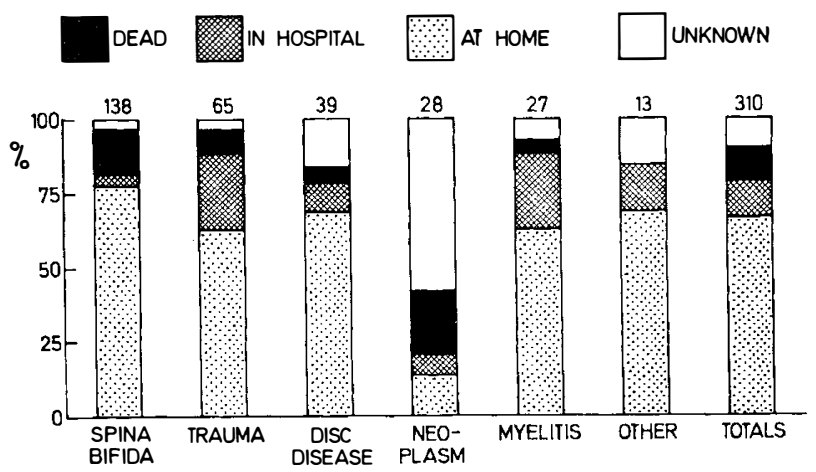

It will be appreciated that these 3 Io patients were admitted during the year 1968, and therefore were only studied over a relatively short period of time, but 
the situation at the end of that year (Table VI) showed that 65 per cent. had returned home, I4 per cent. were still in hospital, I I per cent. had died, and insufficient information was available in some ro per cent. It is of particular note that more than 75 per cent. of the patients with spina bifida and more than 55 per cent. with spinal injuries had returned home at the end of the year.

\section{DISCUSSION}

The frequency of spinal paralysis is not known, and certainly the figures in this series are an underestimate as many patients with spinal paralysis in the catchment area must have been referred to units not involved in this particular study. Unfortunately there is no simple way to discover the incidence of spinal paralysis, and certainly the International Classification of Disease (1967) has not enabled us to obtain a clear idea of the incidence and aetiology of spinal paralysis. There would be great merit in making spinal paralysis a 'notifiable' condition.

We have not encountered a similar study; but Wilcox et al. (1970) analysed 423 consecutive patients admitted to their department over a four-year period, but these did not include 'emergency' admissions. The lesion was traumatic in 348 patients and non-traumatic in 75 (30 neoplasms, 8 intervertebral disc lesions, 6 spondylosis, 2 syringomyelia, 2 tuberculosis, and 2 osteo-myelitis of the spine). Of these 75 patients $4 \mathrm{I}$ were males and 34 were females.

In a report on 3000 selected patients from the National Spinal Injuries Centre, Stoke Mandeville Hospital, Guttmann in 1967 , noted that $1963(65.4$ per cent.) had spinal trauma, I59 (5.3 per cent.) transverse myelitis, I52 (5.I per cent.) poliomyelitis, I2I (4 per cent.) multiple sclerosis, IO6 (3.5 per cent.) vascular process, 62 (2.I per cent.) spina bifida, 33 (I-I per cent.) disc lesions, and 404 cases (13.5 per cent.) had miscellaneous disorders of the spine. These figures contrast with ours, which underline a wider spectrum of medical and surgical disorders.

Michaelis in 1967 estimated that about Io new paraplegic patients would be seen each year per million of the population of a country; and Gregg (I967) found that in Ireland 35 accident cases resulting in paraplegia were being seen in a year, and probably an equivalent number of non-traumatic cases; and that the ratio of males to females was four to one. The incidence of spinal paralysis in Ireland appears to be low.

As we have mentioned, this paper represents a preliminary survey and is an attempt to obtain some useful information so that plans may be formulated to develop suitable new facilities for those with spinal paralysis, taking into account all aspects of the problem, including the type of initial investigation and care that may be required, and the subsequent management of the patients, and also the teaching, research and preventative aspects. One of us (Harris, I967) in a previous communication has outlined the organisation of spinal units; and those of us working in the field of spinal paralysis in Edinburgh, the authors of this paper, have realised that further information regarding the incidence and aetiology of spinal paralysis is necessary before more detailed plans for the development of spinal paralysis services can be formulated.

It is known that increasing numbers of young paraplegic patients are now surviving birth and their first year of life, and will therefore become adult patients. Lorber (1970) reports that in Sheffield where every infant with a myelomeningocele is subjected to early operation, 73 per cent. are alive more than two years later. 
At the other end of the age spectrum, cervical intervertebral disc disease is resulting in a significant increase of elderly tetra-paretic patients. In addition, as a result of the successful management of younger paraplegic patients, many of these patients are getting older and are therefore presenting more challenging problems in the medico-social sphere.

\section{REFERENCES}

GregG, T. (1967). Int. F. Paraplegia, 5, 185.

Guttmann, L. (1967). Int. F. Paraplegia, 5, I I5-126.

HARRIS, P. (1967). Int. F. Paraplegia, 5, I 32-1 37.

INTERNATIONAL Classification OF DisEASES (1967). World Health Organisation, Geneva, Switzerland.

LORBER, J. (I970). Selection for Treatment of Infants with Spina Bifida Cystica. Paper read at the 14th Annual Meeting of the Society for Research into Hydrocephalus and Spina Bifida.

Michaelis, L. S. (1967). Int. F. Paraplegia, 5, I80-181.

Wilcox, N. Elane, Stauffer, E. S. \& Nickel, V. L. (I970). I Jan. I964 through 3 I Dec. 1967. Int. F. Paraplegia, 8, 27-35. 